\title{
Increasing dietary fish intake has contributed to decreasing mortality from CHD among the older population in Hong Kong
}

\author{
Xin-Hua Zhang ${ }^{1, *}$, Jean Woo ${ }^{1,2}$ and Richard F Heller ${ }^{3}$ \\ 'Department of Community and Family Medicine, Chinese University of Hong Kong, Hong Kong SAR, People's \\ Republic of China: ${ }^{2}$ Department of Medicine and Therapeutics, Chinese University of Hong Kong, Hong Kong \\ SAR, People's Republic of China: ${ }^{3}$ Evidence for Population Health Unit (RH), School of Medicine, University of \\ Manchester, Manchester, UK
}

Submitted 18 September 2006: Accepted 26 April 2007: First published online 7 0ctober 2008

\begin{abstract}
Objective: To test whether change in the frequency of fish intake at population level would affect the trends of death from CHD and how many CHD events could be prevented in Hong Kong, a population among those with the highest fish consumption and the lowest CHD mortality in the world.

Design: Time trends analysis with data from repeated dietary surveys and death registration.

Setting: Hong Kong SAR, People's Republic of China.

Subjects: A total of 3096 men and women aged 40-69 years who participated in territory-wide surveys in 1995 or 2003 were included in the analysis of changes in dietary fish intake; all adults aged 40-69 years in Hong Kong were included in the analysis of time trends of CHD mortality.

Results: Over the period, the frequency of fish intake increased and CHD mortality decreased significantly in the population age group of 50-69 years, while in the age group of 40-49 years little change in both fish intake and CHD mortality was observed. It was estimated that $240 \mathrm{CHD}$ deaths (or $29 \%$ of the total) were avoided among the population aged 40-69 years in 2003, as more than half of the population consumed fish every day in Hong Kong.

Conclusions: The time trend of CHD mortality was inversely related to the trend of fish intake. The frequency of fish intake may have a substantial impact on the population for the prevention of CHD deaths in Hong Kong.
\end{abstract}

\author{
Keywords \\ Dietary fish intake \\ Coronary heart disease \\ Population impact
}

The protective effect of dietary fish intake on CHD, partly through the pathway of $n$ - 3 PUFA and especially EPA and DHA, has been explored in general populations as well as among CHD patients for almost half a century. The inverse association between fish consumption and CHD has been observed in both Eastern and Western populations $^{(1-6)}$. A dose-response relationship between the size of the effect on CHD and the amount of fish consumed or the frequency of dietary fish intake was demonstrated in a meta-analysis of thirteen cohort studies ${ }^{(7)}$. Dietary fish intake has been recommended in guidelines on CVD prevention by many medical societies around the world $^{(8-11)}$. However, whether changes in the frequency of fish intake at population level would affect the trends of CHD, and what proportion or number of CHD deaths could be averted due to the frequency of fish intake in a given population, has not been assessed.

The population of Hong Kong is among those with the highest fish consumption and the lowest CHD mortality in the world. The percentage of dietary energy from fish intake in Hong Kong was the third highest and the ageadjusted CHD mortality was the second lowest among those populations with data available in the $\mathrm{UN}^{(12)}$. The population impact of fish intake on CHD mortality in Hong Kong, however, has not been quantitatively estimated. The present report aims to fill this gap by comparing the frequency of daily fish intake and CHD mortality in age- and sex-specific populations between two time points (1995 v. 2003), and estimating the potential population impact of fish intake on CHD deaths in Hong Kong, using recently described measures ${ }^{(13)}$.

\section{Methods}

\section{Data sources}

The frequency of daily fish intake in the Hong Kong population was obtained from two independent surveys 
conducted in Hong Kong in 1995 and 2003. Detailed methods have been described previously ${ }^{(14,15)}$. The first was the Adult Dietary Survey, which was conducted with a sub-sample of the territory-wide cardiovascular risk factor study in Hong Kong from 1995 to $1996^{(14)}$. In brief, 1010 subjects aged 25-74 years were recruited for the dietary survey using an interviewer-administered questionnaire. The frequency and number of standard portions of food taken during the previous week were recalled. There were thirty-one different fish or shellfish and fish products included in the questionnaire. The second survey was conducted in 2003 as part of a study on positive ageing, and comprised a group of 2970 subjects aged 40-74 years living in various regions of Hong Kong ${ }^{(15)}$. In this latter survey, only the frequency of fish intake during the previous week was inquired with the same kind of fish and fish products included in the questionnaire, but no detailed information on the amounts of fish consumed was collected. Therefore, the present analysis compared only the prevalence of daily fish intake (fish consumed for at least one meal per day during the previous week) in the population. The subjects younger than 40 years or older than 69 years were excluded, as the survey in 1995 included only six subjects aged 70 years and over, and the survey in 2003 did not include subjects younger than 40 years. In total, 641 subjects in 1995 and 2455 in 2003 were included in the analysis to compare the prevalence of daily fish intake by the population aged 40-69 years at the two time points.

The time trends of CHD mortality for the Hong Kong population in the same age classes in 1995 and 2003 were analysed using data from vital statistics provided by the Department of Health, Hong Kong Special Administrative Region $^{(16)}$. The International Classification of Diseases (ICD) version 9 was used before 2001 and ICD version 10 was used from 2001 onwards to code the underlying causes of deaths. Mortality from CHD (ICD9 codes 410-414, ICD10 codes I20-I25) in 5-year age groups by gender was included in the analysis.

\section{Statistical analysis}

The frequency (\%) of daily fish intake was compared between 1995 and 2003 among age (40-49 years, 50-59 years, 60-69 years) and sex subgroups. The $\chi^{2}$ test was applied to examine the statistical significance of differences in frequency and the trends of changes.

The CHD mortality (per 100000 per year) was adjusted according to the age structure in 2003 and averaged over three years (the year before and after, and the point year) to reduce the natural fluctuation. The annual percentage change in mortalities was estimated with Poisson's regression analysis.

The population impact of daily fish intake on CHD mortality for one year among the Hong Kong population was estimated using the formula of PIN-ER- $t$ (population impact number, over time $t$, of eliminating risk) suggested by Heller et $a l^{(13)}$ :

$$
\text { PIN-ER-1 }=n \times \text { Ip } \times \text { PAR, }
$$

with

$$
\mathrm{PAR}=\frac{\operatorname{Pe}(\mathrm{RR}-1)}{1+\operatorname{Pe}(\mathrm{RR}-1)},
$$

where $n$ is the population size, Ip is the incidence of CHD deaths in the Hong Kong population, PAR is the population-attributable risk, Pe is the prevalence of daily fish intake estimated from the dietary survey in 2003 and RR is the relative risk of $\mathrm{CHD}$ for people who ate daily compared with those who consumed fish less than once monthly. RR of $0 \cdot 62$ (95\% CI 0•46, 0.82), with adjustment for major risk factors of $\mathrm{CHD}$, was adopted from the metaanalyses of thirteen large cohort studies ${ }^{(7)}$. The same RR was applied to the estimation of the population impact number in one year (PIN-ER-1) for men and women and for the three age groups, as the meta-analysis showed that the RR was not statistically significantly different between gender or age groups ${ }^{(7)}$.

\section{Results}

\section{Trends in dietary fish intake}

In the two surveys, more than $50 \%$ of participants ate fish in at least one daily meal during the previous $7 \mathrm{~d}$ (Table 1). The prevalence was not statistically different between men and women or between the two time points (1995 v. 2003). However, the frequency of daily fish intake tended to decrease in the younger age group $(-1.5 \%$ for men and $-5.9 \%$ for women) but to increase among the older age groups $(9 \cdot 1 \%$ for men and $12 \cdot 7 \%$ for women); the trends of fish intake by age group were statistically significant $(P<0 \cdot 05)$.

\section{Trends of CHD mortality}

Table 2 presents the time trends of CHD mortality, compared between 1995 and 2003. In the age group of 40-49 years, CHD mortality levelled off for men and women during the 8-year period; however, it decreased by $29-38 \%$ (5\% annually) in women and by $27-28 \%$ (4\% annually) in men in the age groups of 50-59 years and 60-69 years.

The time trends of frequency of daily fish intake were contrary to the trends of CHD mortality among the subgroups of population in Hong Kong.

\section{Population impact of daily fish intake on CHD mortality}

The number of CHD deaths that might have been prevented due to daily fish intake in the subgroups of population in Hong Kong in 2003 was estimated with PIN-ER-1 (Table 3). Among 2.6 million adults aged 40-69 years, with more than $51 \%$ of the population consuming 
Table 1 Frequency of daily fish intake in the adult population, Hong Kong, 1995 and 2003

\begin{tabular}{|c|c|c|c|c|c|c|c|}
\hline \multirow[b]{2}{*}{ Sex/age group } & \multicolumn{3}{|c|}{1995} & \multicolumn{3}{|c|}{2003} & \multirow[b]{2}{*}{ Difference (2003-1995) } \\
\hline & $n$ & Frequency (\%) & $95 \% \mathrm{Cl}$ & $n$ & Frequency (\%) & $95 \% \mathrm{Cl}$ & \\
\hline \multicolumn{8}{|l|}{ Men } \\
\hline $40-49$ years & 152 & $52 \cdot 6$ & $44 \cdot 7,60 \cdot 5$ & 280 & $51 \cdot 1$ & $45 \cdot 2,57 \cdot 0$ & $-1 \cdot 5$ \\
\hline 50-59 years & 93 & $58 \cdot 1$ & $48 \cdot 1,68 \cdot 1$ & 355 & $57 \cdot 5$ & $52 \cdot 4,62 \cdot 6$ & -0.6 \\
\hline $\begin{array}{l}60-69 \text { years } \\
P \text { for trend }\end{array}$ & 75 & $56 \cdot 4$ & $45 \cdot 2,67 \cdot 6$ & 308 & $65 \cdot 5$ & $60 \cdot 2,70 \cdot 8$ & $\begin{array}{c}9.1 \\
<0.05\end{array}$ \\
\hline \multicolumn{8}{|l|}{ Women } \\
\hline $40-49$ years & 149 & $64 \cdot 4$ & $56 \cdot 7,72 \cdot 1$ & 593 & $58 \cdot 5$ & $54 \cdot 5,62 \cdot 5$ & -5.9 \\
\hline $50-59$ years & 102 & $59 \cdot 8$ & $50 \cdot 3,69 \cdot 3$ & 456 & $62 \cdot 5$ & $58 \cdot 1,66 \cdot 9$ & $2 \cdot 7$ \\
\hline $\begin{array}{l}60-69 \text { years } \\
P \text { for trend }\end{array}$ & 70 & $57 \cdot 5$ & $45 \cdot 9,69 \cdot 1$ & 463 & $70 \cdot 2$ & $66 \cdot 0,74 \cdot 4$ & $\begin{array}{l}12 \cdot 7 \\
<0 \cdot 001\end{array}$ \\
\hline
\end{tabular}

Table 2 Time trends of CHD mortality rate (per 100000 per year) by age and sex in Hong Kong, 1995-2003

\begin{tabular}{|c|c|c|c|c|c|c|c|c|}
\hline \multirow[b]{3}{*}{ Age group } & \multicolumn{4}{|c|}{ Men } & \multicolumn{4}{|c|}{ Women } \\
\hline & \multicolumn{2}{|c|}{ Mortality rate } & \multicolumn{2}{|c|}{ Change (\%) } & \multicolumn{2}{|c|}{ Mortality rate } & \multicolumn{2}{|c|}{ Change (\%) } \\
\hline & 1995 & 2003 & Over 8 years & Annualt & 1995 & 2003 & Over 8 years & Annualt \\
\hline $40-49$ years & $12 \cdot 4$ & $14 \cdot 3$ & $15 \cdot 3$ & $0 \cdot 4$ & $2 \cdot 5$ & $2 \cdot 1$ & $-16 \cdot 0$ & $-1 \cdot 3$ \\
\hline $50-59$ years & $59 \cdot 1$ & $43 \cdot 3^{*}$ & $-26 \cdot 7$ & $-3 \cdot 8$ & $12 \cdot 6$ & $9 \cdot 0^{*}$ & $-28 \cdot 6$ & $-4 \cdot 5$ \\
\hline $60-69$ years & $184 \cdot 9$ & $132 \cdot 2^{\star \star \star}$ & $-28 \cdot 5$ & $-4 \cdot 0$ & $84 \cdot 7$ & $52 \cdot 2^{\star \star \star}$ & $-38 \cdot 4$ & $-5 \cdot 4$ \\
\hline$P$ for trend & \multicolumn{4}{|c|}{$<0.05$} & & & \multicolumn{2}{|c|}{$<0.05$} \\
\hline
\end{tabular}

Significantly different compared with $1995:{ }^{\star} P<0.05,{ }^{* \star \star} P<0.001$.

tAnnual percentage change in CHD mortality was estimated with a Poisson regression model.

Table 3 Impact of daily fish intake on CHD deaths in the Hong Kong population, 2003

\begin{tabular}{|c|c|c|c|c|c|}
\hline Sex/age group & Population $\left(\times 10^{3}\right)$ & No. of $\mathrm{CHD}$ deaths & $\begin{array}{c}\text { Frequency of } \\
\text { daily fish intake (\%) }\end{array}$ & PARt (\%) & PIN-ER-1f \\
\hline \multicolumn{6}{|l|}{ Men } \\
\hline 40-49 years & 634 & 90 & 51 & 24 & 22 \\
\hline 50-59 years & 405 & 175 & 58 & 28 & 49 \\
\hline 60-69 years & 252 & 333 & 66 & 33 & 110 \\
\hline \multicolumn{6}{|l|}{ Women } \\
\hline 40-49 years & 675 & 14 & 59 & 29 & 4 \\
\hline $50-59$ years & 389 & 35 & 63 & 31 & 11 \\
\hline $60-69$ years & 230 & 120 & 70 & 36 & 44 \\
\hline Total & 2585 & 767 & 59 & 29 & 240 \\
\hline
\end{tabular}

TPAR (population-attributable risk) $=[\mathrm{Pe}(\mathrm{RR}-1)] /[1+\mathrm{Pe}(\mathrm{RR}-1)]$, where $\mathrm{Pe}$ is the prevalence of daily fish intake and $\mathrm{RR}$ is relative risk $(=0 \cdot 62)$. ‡PIN-ER-1 (population impact number, over 1 year, of eliminating risk) = number of deaths avoided due to daily fish intake in the population for 1 year.

fish every day and 767 CHD deaths recorded in the Hong Kong population in 2003, we estimated that about 240 CHD deaths (or 29\% of the total) were avoided in the population aged 40-69 years in 2003 in Hong Kong. In other words, 240 more CHD deaths would have occurred if those who consumed fish every day did not do so in 2003. The benefit increased with age and was more prominent in men. This reflects higher CHD death rates among men and in older age groups.

\section{Discussion}

Compared with the same age groups in 1995, the frequency of daily fish intake decreased slightly in the population aged 40-49 years but increased in the population aged
50-69 years in 2003; in contrast, CHD mortality changed insignificantly in the younger age group but decreased remarkably in the older age group in Hong Kong. More than half of the middle-aged population in Hong Kong ate fish every day, and this contributed to 240 less CHD deaths (29\% of the total) in 2003.

\section{Strength and weaknesses}

The territory-wide dietary surveys in 1995 and 2003 provided the opportunity to track the trend in frequency of dietary fish intake for the same age groups over the time and to estimate its impact on CHD mortality. Free access to public health services for the whole population and the standard death registration and classification system in Hong Kong ensured the reliability of the data on CHD mortality. In the estimation of population impact of 
dietary fish intake on CHD deaths, we used the RR from the pooled estimate from thirteen large cohort studies, including a Chinese cohort ${ }^{(7)}$, with adjustment for other common risk factors of CHD. This should be more reliable than the estimate from an individual cohort study alone.

One of the weaknesses is that the difference in prevalence of fish intake at the two time points may be not really representative of the general population in Hong Kong as the sampling methods differed in the two surveys: the subjects from the first survey in 1995 were randomly drawn from a multistage sampling frame, while in 2003 the subjects were invited from communities in each area without random selection. However, the difference, if any, should not be substantial since the age- and sex-specific prevalence of smoking obtained from the surveys were similar to those from large-scale surveys conducted by government agencies during the same time period.

Time lag was not taken into account in the analysis as dietary fish intake obtained from the food frequency survey during the last $7 \mathrm{~d}$ was assumed to be representative of long-term dietary habits, rather than a one-off or a short-period exposure.

The types of fish (e.g. fatty fish, which contain more $n-3$ fatty acids than lean fish, or salted fish, which may cause more harm than good) and the amount of fish intake were not collected in the 2003 survey; thus the effect of changing fish type or intake amount could not be addressed in the analysis.

There might be other confounding factors influencing the relationship between time trends of fish intake and that of CHD mortality as demonstrated. If the change in fish intake had been associated with changes in other aetiological or preventive exposures, these might at least partly account for the associations with CHD trends.

The advance in clinical management (earlier and more precise diagnoses and improvement of treatment) is an important contributor to the general decrease of $\mathrm{CHD}$ deaths in Hong Kong, but it could not explain the discrepancy of the trends of CHD mortality between the younger and the older age groups: the improvement has no reason to benefit only the older age group.

The uncertainty of the diagnoses of death from CHD should also be taken into account. However, the more notable decrease in all-cause mortality and total cardiovascular mortality observed in the Hong Kong population indicated that the changing trends in CHD mortality could not be due to the switching of diagnosis from other causes.

Other lifestyle-related risk factors could also have played important roles in the discrepancies of the CHD trends. For example, smoking and physical inactivity changed during the period. Data from the same surveys conducted in 1995 and 2003 indicated that the prevalence of smoking decreased and that of physical exercise ( $\geq 30 \mathrm{~min} / \mathrm{d}$ ) increased more in the older age group for both men and women but less in the younger age group in men, while the favourable change did not occur in younger aged women; thus the prevalence of smoking increased and that of leisure-time physical exercise decreased (data not shown here). These trends in prevalence of smoking and physical exercise could explain the discrepancy in CHD trends between age groups, but could not explain the gender differences.

\section{Possible mechanisms and implications for policy makers}

Previous ecological studies have indicated that fish consumption is related inversely to CHD mortality in different countries $^{(12,17)}$ and prospective cohort studies have shown that individuals with high fish intake experience lower incidence of $\mathrm{CHD}$, in both Eastern and Western populations ${ }^{(1,2,4,5,18-21)}$. The current study revealed that increased frequency of fish intake at population level was related to a decrease in CHD mortality. It added more evidence to the protective effect of dietary fish intake on CHD death.

Although some cohort studies did not find a significant effect of fish intake on $\mathrm{CHD}^{(3,22,23)}$, the meta-analysis performed in 2004 revealed no evidence of significant heterogeneity between the cohorts which found protective effects and those which did not, and the pooled results showed a dose-response relationship between fish consumption and CHD deaths ${ }^{(7)}$.

The possible mechanism of the protective effect of fish intake on CHD is partly through $n$-3 PUFA, especially EPA and DHA; both are abundant in fish oil, which has antiarrhythmic, anti-atherogenic and anti-thrombotic effects as tested in laboratories with animals, in clinical trials and in prospective cohort studies ${ }^{(5,24-33)}$. Fish fatty acids as a percentage of total energy intake in the Hong Kong population $(0 \cdot 66 \%)$ was relatively constant during the last half century and higher than that in the USA (0.22\%) and Mediterranean countries like Spain (0.44\%), supporting the theory at population level ${ }^{(34)}$.

However, the effect of $n-3$ fatty acids on total cardiovascular events was inconclusive in a recent published meta-analysis ${ }^{(35)}$. This could be partly due to the analysis combining studies using different $n-3$ fatty acid supplements and different endpoints, since DHA and EPA (not all n-3 PUFA supplements contain both) have different protective effects on patients with different profiles of cardiovascular risk factors and on fatal and non-fatal CHD events ${ }^{(29,33)}$.

The estimates of the population effect of dietary fish intake on CHD deaths in the Hong Kong population in the age group 40-69 years revealed that some 240 (or $29 \%$ of the total) CHD deaths were avoided in 2003 as more than half of the population consumed fish every day. If the population had maintained the same frequency of daily fish intake as it had in 1995, there would have been only 213 CHD deaths averted in 2003. Thus the increasing frequency of dietary fish intake in the older population saved more lives from CHD. 
The current estimation was rather conservative as the RR (0.62) we used in the calculation is for those ate fish more than five times weekly compared with those ate fish less than once monthly. In the real scenario, those who did not take fish every day still took it more than once per month in the Hong Kong population.

Dietary fish intake has been recommended by many guidelines to control or prevent $\mathrm{CVD}^{(8-11)}$. However, the population impact of dietary fish intake on CHD has not been assessed in local populations as it depends largely on the population size, incidence of CHD deaths and the frequency of dietary fish intake locally. The PIN-ER- $t$, which derives absolute numbers of the population impact, is more meaningful than proportions or probabilities to measure the magnitude of the effect, especially in the evaluation of the effect of health promotion and prevention in a given population.

In conclusion, the more favourable trends of CHD mortality in the Hong Kong population aged 50-69 years and less favourable trends in the younger age group may be partly due to the different trends of dietary fish intake. The habit of eating fish every day in the Hong Kong population has contributed substantially to the prevention of CHD mortality. Encouraging fresh fish intake among the younger population, but avoiding contaminated or salty fish, could help reduce the burden of CHD.

\section{Acknowledgements}

The project was partly supported by a Direct Grant from the Chinese University of Hong Kong. X.-H.Z. designed the study, did the analysis, interpreted the results and drafted the manuscript. J.W. and R.F.H. interpreted the results and revised the manuscript. All authors approved the final version of the manuscript. There is no conflict of interest for any author.

\section{References}

1. Kromhout D, Bosschieter E \& de Lesenne Coulander C (1985) The inverse relation between fish consumption and 20-year mortality from coronary heart disease. N Engl J Med 312, 1205-1209.

2. Daviglus M, Stamler J, Orencia A, Dyer A, Alan R, Liu K, Greenland P, Walsh M, Morris D \& Shekelle R (1997) Fish consumption and the 30-year risk of fatal myocardial infarction. $N$ Engl J Med 336, 1046-1053.

3. Albert C, Hennekens C, O'Donnell C, Ajani U, Carey V, Willett W, Ruskin J \& Manson J (1998) Fish consumption and risk of sudden cardiac death. JAMA 279, 23-28.

4. Yuan J, Ross R, Gao Y \& Yu M (2001) Fish and shellfish consumption in relation to death from myocardial infarction among men in Shanghai, China. Am J Epidemiol 154, 809-816.

5. Iso H, Kobayashi M, Ishihara J, Sasaki S, Okada K, Kita Y, Kokubo Y \& Tsugane S for the JPHC Study Group (2006) Intake of fish and $n-3$ fatty acids and risk of coronary heart disease among Japanese: the Japan Public Health Centerbased (JPHC) study cohort I. Circulation 113, 195-202.

6. Jarvinen R, Knekt P, Rissanen H \& Reunanen A (2006) Intake of fish and long-chain $n$-3 fatty acids and the risk of coronary heart mortality in men and women. Br J Nutr $\mathbf{9 5}$, $824-829$.

7. He K, Song Y, Daviglus M, Liu K, Van Horn L, Dyer A \& Greenland P (2004) Accumulated evidence on fish consumption and coronary heart disease mortality: a metaanalysis of cohort studies. Circulation 109, 2705-2711.

8. Backer G, Ambrosioni E, Borch-Johnsen K, Brotons C, Cifkova R, Dallongeville J et al. (2006) European guidelines on cardiovascular disease prevention in clinical practice. Third joint task force of European and other societies on cardiovascular disease prevention in clinical practice. Eur J Cardiovasc Prev Rehabil 10, Suppl. 1, S1-S78.

9. Krauss R, Eckel R, Howard B et al. (2000) AHA Dietary Guidelines revision 2000: a statement for healthcare professional from the nutrition committee of the American Heart Association. Circulation 102, 2284-2299.

10. Ministry of Public Health, CVD Control and Research Center, Chinese Hypertension League (2005) Guideline for Hypertension Control and Prevention. Beijing: Ministry of Public Health.

11. Pearson T, Blair S, Daniels S et al. (2002) AHA guidelines for primary prevention of cardiovascular disease and stroke: 2002 update: consensus panel guide to comprehensive risk reduction for adult patients without coronary or other atherosclerotic vascular diseases. Circulation 106, 388-391.

12. Zhang J, Sasaki S, Amano K \& Kesteloot H (1999) Fish consumption and mortality from all causes, ischemic heart disease, and stroke: an ecological study. Prev Med 28, 520-529.

13. Heller R, Buchan I, Edwards R, Lyratzopoulos G, McElduff P \& Leger S (2004) Communicating risks at the population level: application of population impact numbers. BMJ327, $1162-1165$.

14. Woo J, Leung S, Ho S, Sham A, Lam T \& Janus ED (1997) Dietary practices and lipid intake in relation to plasma lipid profile in Hong Kong Chinese. Eur J Clin Nutr 51, 467-471.

15. Woo J (2008) Lifestyle and positive ageing. In Positive Ageing [S Ng, J Woo, A Kwan and A Chong, editors]. Hong Kong SAR: City University Press (In the Press).

16. Department of Health (2006) Vital Statistics in Hong Kong. Healthy Hong Kong. Hong Kong SAR: Department of Health; available at http://www.healthyhk.gov.hk/phisweb /en/enquiry/index.html

17. Menotti A, Kromhout D, Blackburn H, Fidanza F, Buzina R \& Nissinen A (1999) Food intake patterns and 25-year mortality from coronary heart disease: cross-cultural correlations in the Seven Countries Study. Eur J Epidemiol 15, 507-515.

18. Rodriguez B, Sharp D, Abbott R, Burchfiel C, Masaki K, Chyou P-H, Huang B, Yano K \& Curb J (1996) Fish intake may limit the increase in risk of coronary heart disease morbidity and mortality among heavy smokers. Circulation 94, 952-956.

19. Oomen C, Feskens E, Edith J, Rasanen L, Fidanza F, Nissinen A, Menotti A, Kok F \& Kromhout D (2000) Fish consumption and coronary heart disease mortality in Finland, Italy, and the Netherlands. Am J Epidemiol 151, 999-1006.

20. Mozaffarian D, Lemaitre R, Kuller L, Burks G, Tracy R \& Siscovick D (2003) Cardiac benefits of fish consumption may depend on the type of fish meal consumed, the cardiovascular health study. Circulation 107, 1372-1377.

21. Erkkila A, Lichtenstein A, Mozaffarian D \& Herrington D (2004) Fish intake is associated with a reduced progression 
of coronary artery atherosclerosis in postmenopausal women with coronary artery disease. Am J Clin Nutr 80, 626-632.

22. Mann J, Appleby P, Key T \& Thorogood M (1997) Dietary determinants of ischaemic heart disease in health conscious individuals. Heart 78, 450-455.

23. Osler M, Andreasen A \& Hoidrup S (2003) No inverse association between fish consumption and risk of death from all-causes, and incidence of coronary heart disease in middle-aged, Danish adults. J Clin Epidemiol 56, 274-279.

24. Demaison L \& Moreau D (2002) Dietary $n$-3 polyunsaturated fatty acids and coronary heart disease-related mortality: a possible mechanism of action. Cell Mol Life Sci 59, 463-477.

25. Harper C \& Jacobson T (2001) The fats of life: the role of omega- 3 fatty acids in the prevention of coronary heart disease. Arch Intern Med 161, 2185-2192.

26. Xiao Y, Sigg D \& Leaf A (2005) The antiarrhythmic effect of $n-3$ polyunsaturated fatty acids: modulation of cardiac ion channels as a potential mechanism. J Membr Biol 206, 141-154.

27. Hallgren C, Hallmans G, Jansson J, Marklund S, Huhtasaari F, Schütz A, Strömberg U, Vessby B \& Skerfving S (2001) Markers of high fish intake are associated with decreased risk of a first myocardial infarction. Br J Nutr 86, 397-404.

28. Hu F, Bronner L, Willett W, Stampfer M, Rexrode K, Albert C, Hunter D \& Manson J (2002) Fish and omega-3 fatty acid intake and risk of coronary heart disease in women. JAMA 287, 1815-1821.
29. Lemaitre R, King I, Dozaffarian D, Kuller L, Tracy R \& Siscovick D (2003) n-3 Polyunsaturated fatty acids, fatal ischemic heart disease, and nonfatal myocardial infarction in older adults: the cardiovascular health study. Am J Clin Nutr 77, 319-325.

30. Rissanen T, Voutilainen S, Nyyssonen K, Lakka T \& Salonen J (2000) Fish oil-derived fatty acids, docosahexaenoic acid and eicosapentaenoic acid, and the risk of acute coronary events: the Kuopio ischaemic heart disease risk factor study. Circulation 102, 2677-2679.

31. Erkkila A, Lehto S, Pyorala K \& Uusitupa M (2003) n-3 Fatty acids and 5-y risks of death and cardiovascular disease events in patients with coronary artery disease. Am J Clin Nutr 78, 65-71.

32. Hu F, Cho E, Rexrode K, Albert C \& Manson J (2003) Fish and long-chain $n$-3 fatty acid intake and risk of coronary heart disease and total mortality in diabetic women. Circulation 107, 1852-1857.

33. Mori TA \& Woodman RJ (2006) The independent effects of eicosapentaenoic acid and docosahexaenoic acid on cardiovascular risk factors in human. Curr Opin Clin Nutr Metab Care 9, 95-104.

34. Zhang J \& Kesteloot H (2001) Differences in all-cause, cardiovascular and cancer mortality between Hong Kong and Singapore: role of nutrition. Eur J Epidemiol 17, 469-477.

35. Hooper L, Thompson R, Harrison R et al. (2006) Risks and benefits of omega 3 fats for mortality, cardiovascular disease, and cancer: systematic review. BMJ 332, 752-760. 